\title{
Stability of the Brass Cups Forming Process
}

\author{
Martin Zahálka
}
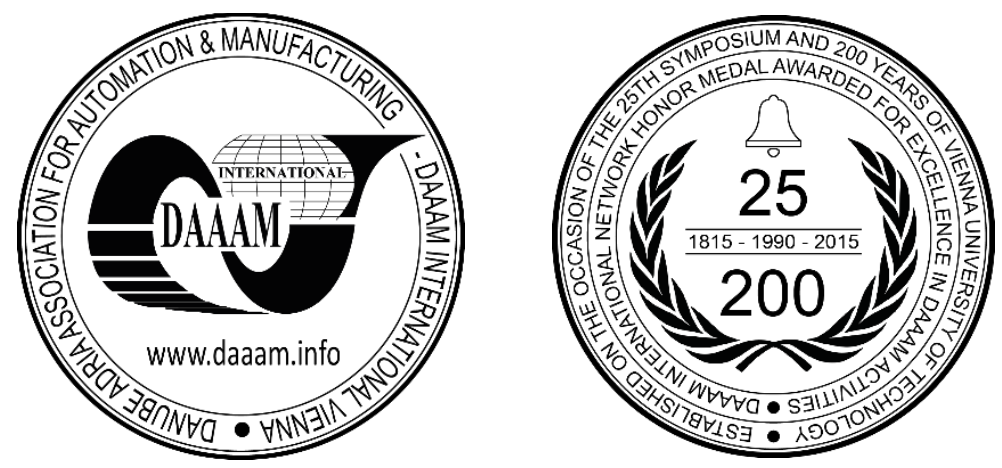

This Publication has to be referred as: Zahalka, M[artin] (2018). Stability of the Brass Cups Forming Process, Proceedings of the 29th DAAAM International Symposium, pp.0435-0439, B. Katalinic (Ed.), Published by DAAAM International, ISBN 978-3-902734-20-4, ISSN 1726-9679, Vienna, Austria DOI: $10.2507 / 29$ th.daaam.proceedings.064

\begin{abstract}
This paper deals with forming of the brass cups. Although brass pressing is very widespread, pressing of cups is not described in more detail in the literature. Existing tooling does not achieve the required accuracy of today's production. Development of new and improved tools are now limited to modifications of existing with uncertain results. This article compares several types of forming tools, which are used for forming of the bass cups, and their influence on the product tolerances. For each tool, the response to change of the input parameters such, as the thickness of the input plate, is also considered. The results are compared with real measured products. The individual tool shapes are analyzed by the Deform 3D software.
\end{abstract}

Keywords: brass; CuZn30; metal forming; forming tool; cartridge

\section{Introduction}

Brass is a well deformable material and because of that is mainly manufactured by usage of cold forming process. It is used for many different applications due to good sliding properties. The result of the manufacturing process of brass can be finished product or a semi-finished product, which is not necessary to be further modified, for example not to be machined.

Precision requirements and tolerances are in this production method in the order of 0,01 millimeters. Therefore, it is necessary to design the forming tools, which are able to keep these parameters even if the input parameters are changed (it means change of the thickness of the sheet metal input or incorrect manufacturing and assembling of the forming tools) [2].

The aim of the research is to compare the generally used tool shapes for drawing a circular brass cup, which serves as a semi-finished product for the production of brass cartridges. The semi-product in the form of a cup is very useful for all cylindrical moldings, but in this application is required the highest accuracy of diameter, the bottom thickness, the wall thickness and the flatness of the free cup end.

Cups manufacturers are using very different design of tolls for production of almost identical cups. Therefore, there was a requirement to compare the properties of the individual tool shapes. This comparison wasn't done up to now. Selecting the shape of the tool is now usually carried out by trial and error. Every manufacturer protects own know-how against his competitors and it is not possible to obtain all necessary information for comparing. 
If we know the effect of the individual shapes in the tool on the final product, it will greatly accelerate the development of the new tools for products of other dimensions. In addition, tool production will be cheaper, because it will not be necessary to make a large number of adjustments like now.

\section{Tool design}

Forming is performed on a double-acting press and this corresponds to the tool design. The tool consists [1] of three parts, Punch, Cutting punch and Matrix. Punch creates internal dimensions of the cup. Cutting punch trim the circular cutting, which is further formed. Dimension of cutting punch affects the weight of the cup. The most important part is matrix, which affects the external shape of the final product. The matrix is the subject of research in this paper.

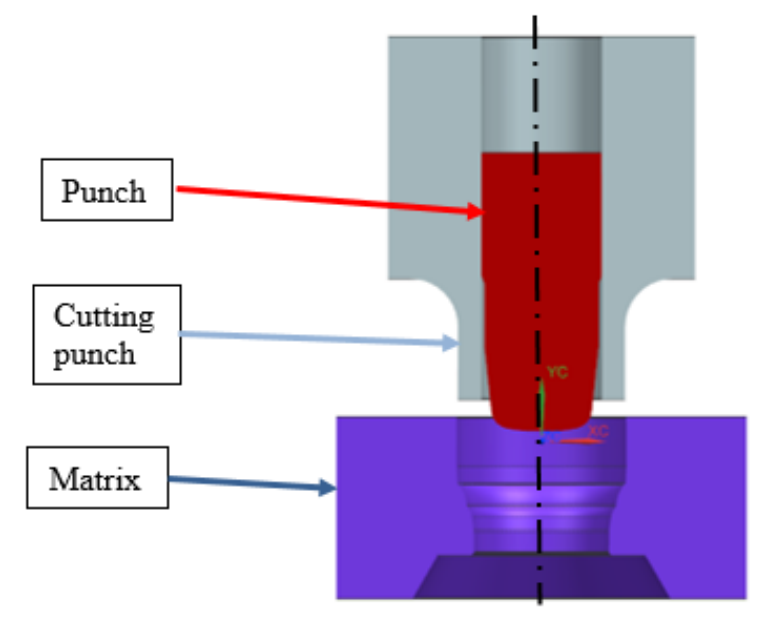

Fig. 1. Construction of the tool

\section{Influences on the forming process}

The forming process is influenced by several parameters [6]. Besides the tool shape they are precision of tool manufacturing, properties of the processed material [5], technological parameters (temperature, lubrication) [4] and many other input parameters are influencing the forming process. Individual influences can be divided into two categories. In one category there are parameters that we can influence by the tool and in the other one are the parameters that is affected by the material.

Tool parameters are: tool shape, shape tolerances (circularity,...), lubrication, adjustment Material parameters are: strength, anisotropy, thickness tolerance [3]

\section{Matrix}

Many tool shapes are used today, as is shown in the fig. 2. Individual shapes are very different and it is necessary to compare their properties.
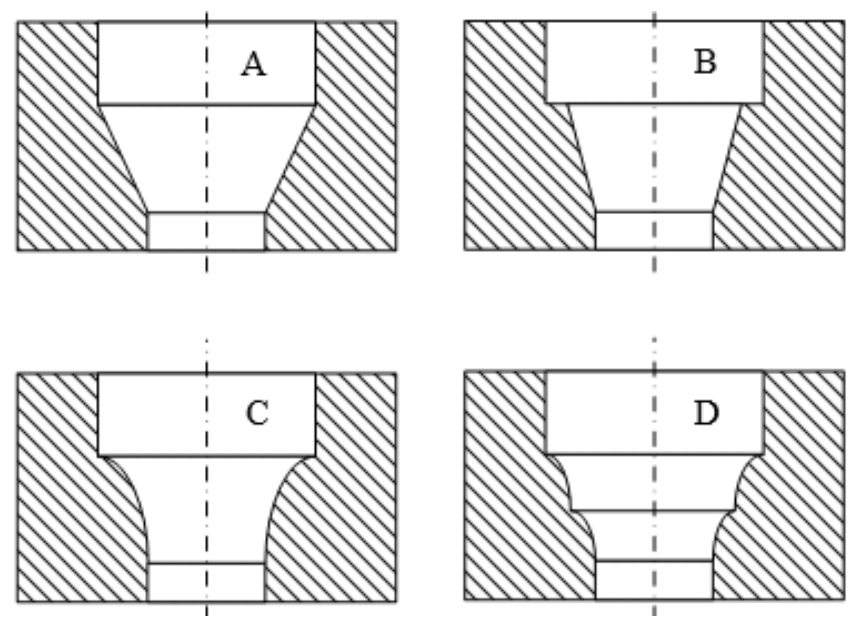

Fig. 2. Tool shapes 
Because it is possible to compare a large number of parameters, two basic, which is difficult to keep the acceptable tolerance. The first parameter is the thickness of the bottom wall and the second is the perpendicular end of the cup to its diameter. These two parameters are analyzed in response to changes of input variables such as the thickness of the sheet and tool cylindricity.

\section{Comparing of the stability of individual shapes}

As has been said, two selected parameters will be compared. Tools are compared for one material thickness of $3 \mathrm{~mm}$ and material CuZn30. Comparison is done using the DEFORM 2D/3D software [7].

\subsection{Influence on the bottom thickness}

The calculation of the effect of the tool on the bottom thickness is complemented by the parameter of the thickness tolerance of the input plate, which also significantly affects the wall thickness. [3] Tolerance of the material thickness is defined as $3 \pm 0,1 \mathrm{~mm}$. The tolerances of rolled sheets are actually smaller. A higher tolerance value is chosen for better clarity.

The calculation of the bottom thickness is solved as a 2D axisymmetric problem. Friction between tool and materiel is 0,05 and the speed of the ram is $0,5 \mathrm{~m} / \mathrm{s}$. The simulation is calculated with the temperature influence, because the material heats during forming.

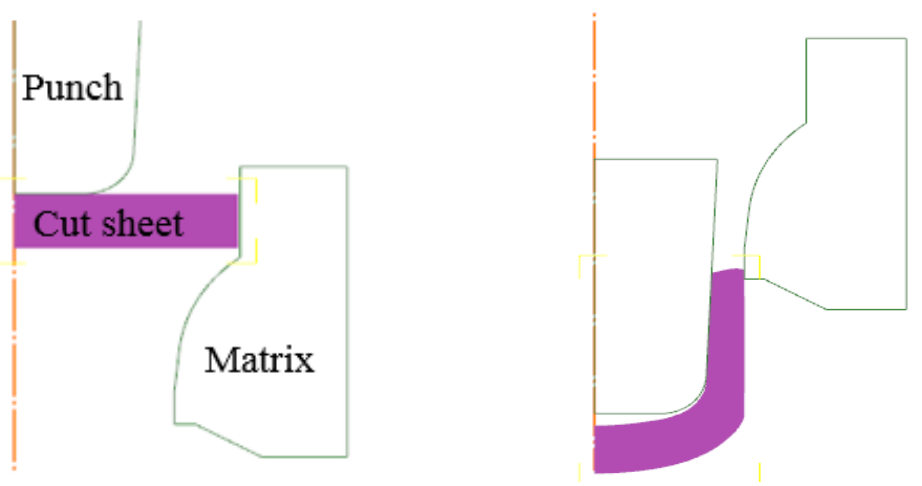

Fig. 3. Tool shapes

The influence of the material thickness to the bottom cup wall is compared in the following table 1.

\begin{tabular}{|c|c|c|c|c|}
\hline Shape/Mat. tolerance & 0 & $+0,1$ & $-0,1$ & $\Delta$ \\
\hline A & 2,87 & 2,98 & 2,78 & 0,20 \\
\hline B & 2,83 & 2,92 & 2,74 & 0,18 \\
\hline C & 2,84 & 2,91 & 2,75 & 0,16 \\
\hline D & 2,84 & 2,93 & 2,75 & 0,18 \\
\hline
\end{tabular}

Table 1. Bottom wall thickness

Individual tool shapes do not show large differences in terms of bottom thickness. The most stable shape is the C. The worst shape is A. Shape A changed the thickness of the bottom wall by $0.2 \mathrm{~mm}$ when changing the input sheet thickness by $0.2 \mathrm{~mm}$. Shape $\mathrm{C}$ changed the thickness of the bottom $0.16 \mathrm{~mm}$ when changing the thickness of the sheet by $0.2 \mathrm{~mm}$. All shapes of tools can achieve the required bottom thickness. The most suitable shape is $\mathrm{C}$.

\subsection{Perpendicularity of the end of the cup}

The poor perpendicularity of the end is caused by some asymmetry during forming. It can be influenced by the geometric precision of the tool, especially circularity or by a crooked cutting out of the sheet metal strip. Because of this asymmetry, this calculation is solved as 3D. All input values are the same as in previous $2 \mathrm{D}$ simulations.

The asymmetry was made in calculating by shifting of cut sheet from the middle of the matrix by $0.1 \mathrm{~mm}$. We do not now deal with the origin of asymmetry, but the ability of the tool to correct this error. Therefore, this procedure for creating an error for comparing individual tool shapes is sufficient. Real samples, which have poor values of perpendicularity, from forming with the tool shape $\mathrm{C}$ are available for the following control of the simulation. The free end of the cup was measured by the difference between the highest and lowest point top surface, as is shown in fig. 5 . 
A

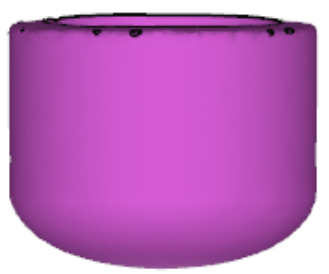

B

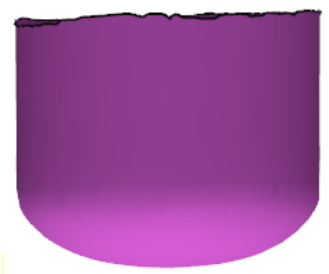

C

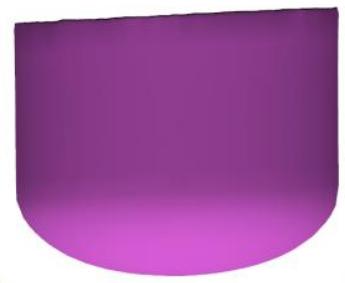

D

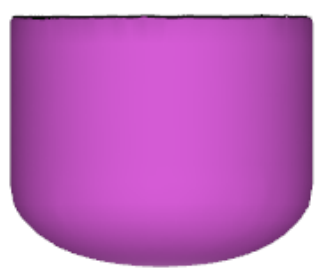

Fig. 4. Final cup shapes

The shape and tolerance of the cup, which was simulated with the tool shape $\mathrm{C}$ is a very similar to reality. This suggests that other simulated shapes that have not been tested in real life are true. The measured average tolerance for the ten real cups is $0.38 \mathrm{~mm}$.

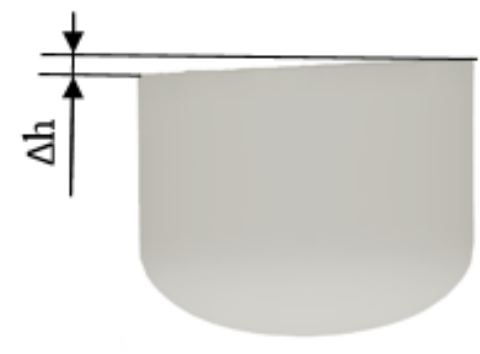

Fig. 5. Measuring of the tolerance

\begin{tabular}{|c|c|}
\hline Shape & $\Delta \mathrm{h}$ \\
\hline A & 0,65 \\
\hline B & 0,41 \\
\hline C & 0,35 \\
\hline D & 0,08 \\
\hline
\end{tabular}

Table 2. Tolerance of the end

The most stable tool shape is $\mathrm{D}$, which has a tolerance of free end of $0.08 \mathrm{~mm}$. Shape A is the worst, because a tolerance of end is $0.65 \mathrm{~mm}$.

\section{Conclusion}

Through the analyzes, it has been found that all the instruments are suitable for achieving the desired bottom thickness. In this view, there is not much difference between the shapes even when is consider the material thickness change. Changing the thickness of the bottom roughly corresponds to the change in the thickness of the input material. In this context, to reduce production of cups with poor bottom thickness, only careful monitoring of the input plates can be recommended.

More interesting is the analysis of the influence of the shape of the tool on the shape of the end of the cup. This comparison brought a clearer view of the problem that occurs very often. Sometimes there are deviations of such values that tools are damaged by mutual contact.

It has been shown that the correct choice of tool shape can eliminate manufacturing or material defects. Some tool shapes with $0.1 \mathrm{~mm}$ eccentricity of the material were far better than others. At this stage of the research, use of shape D may be recommended. Of course it would be appropriate this shape modify and test further.

The bottom thickness and the end of the cup are not the only parameters to be examined for the general view of this problem. It is still necessary, in further research, to check the effect of the tool shape on centricity, diameter, height, etc. This research has provided the basis for further analysis. By the same procedure as described herein, other parameters can be compared. It is also possible to design new tool shapes and extend this research.

\section{Acknowledgments}

The article was supported by the motivation system of the University of West Bohemia, part of the postdoctoral programme [8].

The article has been prepared under project LO1502 'Development of the Regional Technological Institute' under the auspices of the National Sustainability Programme I of the Ministry of Education of the Czech Republic aimed to support research, experimental development and innovation.

\section{References}

[1] Colgan, M.; Monaghan, J. (2003). Deep drawing process: analysis and experiment, Journal of Materials Processing Technology, 132, pp 35-41

[2] Pedersen, J. B. (2017). Process stabilization of cartridge case ironing, Aalborg University, 
[3] Wessely, E; Evin, E \& T. (2012). Prediction of Deformation Properties of Steel Sheets by Numerical Simulation, Chapter 02 in DAAAM International Scientific Book 2012, pp. 019-026, B. Katalinic (Ed.), Published by DAAAM International, ISBN 978-3-901509-86-5, ISSN 1726-9687, Vienna, Austria DOI: 10.2507/daaam.scibook.2012.02019

[4] Gamboa, B. C.; Martin, F.; Sevilla, L. (2012). Friction influence on the implementation of the upper bound theorem in indentation process, B. Katalinic (Ed.), Published by DAAAM International, ISBN 978-3-901509-91-9, ISSN 2304-1382, Vienna, Austria, 2012

[5] Park, H. \& Anh, T. V. (2010). Different Methods In Analyzing Roll Forming Process Of Automotive Component, Chapter 07 in DAAAM International Scientific Book 2010, pp. 057-072, B. Katalinic (Ed.), Published by DAAAM International, ISBN 978-3-901509-74-2, ISSN 1726-9687, Vienna, Austria

[6] Maria, C.; Lima, O.; Sergio, R.\&B. (2000). Application of the finite element method in cold forging processes. Journal of the Brazilian Society of Mechanical Sciences. 22. 10.1590/S0100-73862000000200005.

[7] Raz, K.; Vaclav, K. (2014). Using of hydraulic press in production and manufacturing of large rings, Procedia Engineering, Volume 69, pp. 1064-1069, Published by Elsevier Ltd, ISSN 18777058, DOI: 10.1016/j.proeng.2014.03.091

[8] http://www.zcu.cz/research/Grantovy-system/motivacni-system/2018/cast_POSTDOC_2018, (2018), University of West Bohemia, Accessed on: 2018-07-23. 